\title{
Microstructural Evolution of Cold-Deformed and Isothermally Treated ZA27 Alloys
}

\author{
Wilky Desrosin $^{a, b}$ (D), Gerardo Hector Rubiolo ${ }^{b, c}$, Carlos Enrique Schvezov ${ }^{a, c^{*}}$ (1) \\ ${ }^{a}$ Universidad Nacional de Misiones (UNAM), Consejo Nacional de Investigaciones Cientícias y \\ Técnicas (CONICET), Instituto de Materiales de Misiones (IMAM), Posadas, N3300LQD, Misiones, \\ Argentina \\ ${ }^{b}$ Universidad Nacional de San Martín (UNSAM), Comisión Nacional de Energía Atómica (CNEA), \\ Instituto Sabato, Av. Gral. Paz 1499, B1650KNA, San Martín, Buenos Aires, Argentina \\ ${ }^{c}$ Consejo Nacional de Investigaciones Científicas y Técnicas (CONICET), Godoy Cruz 2290, \\ C1425FQB, Ciudad Autónoma de Buenos Aires, Argentina
}

Received: December 21, 2020; Revised: May 13, 2021; Accepted: May 15, 2021

Pure ZA27 alloys and ZA27 alloys with $\mathrm{Cu}$ and Mg additions were cast and deformed by compression. Samples of both alloys were heat treated at $460^{\circ} \mathrm{C}$ after deformation and the evolution of the microstructure as a function of time measured. The results showed that the average grain size increases with the increase of time for both alloys, with a coarsening rate which is $55 \%$ lower for the alloyed ZA27 alloy than the rate of the pure ZA27 alloy. X-ray diffraction analysis indicated that the ZA27 alloys containing $\mathrm{Cu}$ and $\mathrm{Mg}$ additions present the $\varepsilon$ phase which is not present in the non-alloyed ZA27 alloy; and that the $\alpha$ and $\eta$ phases transform to the $\beta$ phase during heat treatment. Microhardness measurements showed that the ZA27 alloy with $\mathrm{Cu}$ and $\mathrm{Mg}$ additions has higher microhardness than the pure ZA27 alloy.

Keywords: ZA27 alloys, SIMA method, Globular phases, Coarsening and Microharness.

\section{Introduction}

The manufacture of metal, alloys and composites in the semisolid state is a consolidated technology for production of parts and components in several industrial applications. Selecting the optimal processing temperature between the Solidus and Liquidus temperature is the key step in designing the production process. In this case, the semisolid process induces both melting and forging as an integrated process ${ }^{1,2}$. The semisolid process results in a globular rather than dendritic or standard granular microstructure, which is a structure with better mechanical properties ${ }^{3,4}$. This thixotropic microstructure can be achieved by thixocasting and rheocasting normally called thixoprocessing and rheoprocessing, respectively, being the second the most used in practice ${ }^{1-6}$. In order to achieve non-dendritic structures, two procedures have been $\operatorname{proposed}^{7}:$ i) electromagnetic fast pulse discharges and ii) prolonged heat treatment at a temperature in the Mushy temperature region. This last procedure can be applied in two forms: the magnetohydrodynamic process (MHD) and the strain-induced melt activation process (SIMA). SIMA is a thermomechanic process which consists in the introduction of mechanical stresses by plastic deformation at room temperature and transforming the dendritic structure into a globular structure by heat treatment in the Mushy zone. The SIMA process is chosen because its low cost, however limited to producing small parts ${ }^{3,7}$. In SIMA alloys, the final equiaxed microstructure is the result of fragmentation of a heavily deformed initial dendritic microstructure by

*e-mail: schvezov@gmail.com liquid penetration at incipient melting in the high energy boundaries formed in the alloy during the process ${ }^{8}$. In addition, with the increase of the isothermal time, the primary grains disintegrate and the white dendritic cores separate. Furthermore, during the isothermal heat treatment the volume fraction of bright dendritic phase gradually decreases and disappears while the new white globular particles form and increase in quantity ${ }^{2,9}$. As the isothermal time increases, the whole structure is formed by independent spherical grains uniformly distributed in the semisolid alloy. The spherical grains contain black spots which with time merge into the center of the spherical grains ${ }^{9}$ which are called intragranular island or intraglobular zone ${ }^{6}$.

In the present work the microstructural evolution during the SIMA process applied to ZA27 alloys is investigated. The transformation under different processing conditions of the dendritic microstructure into a globular one is analyzed as a coarsening process and compared to the prediction of the ripening theory due to Ostwald. The microhardness of the alloys are measured and analyzed before and after the SIMA process in both the globular and interglobular regions.

\section{Materials and Methods}

ZA27 alloys with and without other alloying elements were produced from commercially pure $\mathrm{Al}, \mathrm{Zn}, \mathrm{Mg}$ and Al-33.2\% Cu master alloys. Two types of ZA27 alloys were investigated: pure ZA27 alloys containing only $\mathrm{Zn}-\mathrm{Al}$ and ZA27 alloys containing $2 \% \mathrm{Cu}$ and $0.015 \% \mathrm{Mg}$ (all chemical compositions are expressed in wt $\%$ (weight $\%)$ ). The alloys 
were prepared by melting the components in a ceramic crucible with an electric furnace at approximately $750{ }^{\circ} \mathrm{C}$ and the molten alloy was stirred manually. The molten alloy was then poured in a metallic mold placed in a sand box at room temperature. The castings had the following dimensions: $2 \mathrm{~cm}$ in height, $3.5 \mathrm{~cm}$ in width and $13.5 \mathrm{~cm}$ in length. The alloy was then cut in the length in samples $2 \mathrm{~cm}$ long, in a total of 6 samples. Each sample was cold deformed by compression $20 \%$ in width.

Each cold deformed sample was then heat treated at $460{ }^{\circ} \mathrm{C}$ in a box-like resistance furnace (Simcic), the sample temperature was measured with a thermocouple in contact with the sample and the temperature tolerance was kept within $\pm 1^{\circ} \mathrm{C}$. This temperature is nearby the middle of the range between Solidus $\left(440 \pm 2{ }^{\circ} \mathrm{C}\right)$ and Liquidus $\left(490 \pm 1^{\circ} \mathrm{C}\right)$ temperatures for the pure ZA27 alloy ${ }^{1,2,8}$. For each alloy, deformed samples were heat treated in the semisolid state during five different times: 15, 20, 30, 45 and 60 minutes. After heat treatment, the samples in the semisolid state were rapidly quenched in water at room temperature to freeze the liquid phase in place and preserve the morphology of the microstructure.

For metallographic observation the samples were polished using standard metallographic techniques. The microstructure was revealed by etching the polished surface with a $4 \%$ Nitric Acid solution during 5 seconds. The sample surfaces were observed with an optical microscope (Zeiss Axio Lab A1) and Scanning Electron Microscopy (SEM FEI Quanta 200). The average grain size was measured using the procedure given by the ASTM E112 standard. The microstructure was measured at different depths from the exposed surface in order to determine, first; if there is a surface effect in the microstructure due to surface diffusion instead of volume diffusion and second, in case there is no superficial effect on the dimensions, use an approximation of pseudo-cylindrical planar symmetry to estimate the volume fraction of each phase. The elements $\mathrm{Zn}, \mathrm{Al}$ and $\mathrm{Cu}$ were mapped by EDAX to determine the time evolution of the elements distribution in the present phases. Finally, a PAN analytical diffractometer model Empyrean and an automated multipurpose X-Ray diffractometer (XRD), Rigaku SmartLab were used for the $\mathrm{XRD}$ analysis to determine the phases evolutions from as cast, after deformation and during heat treatment for both alloys.

A grain size study was performed using statistical adjustment for the distribution of the grains of the two alloys named above. The microhardness of the alloys was measured with a Future Tech Microhardness Tester FM800. Previous to the test, the surface was polished using standard metallographic techniques, the applied load was $25 \mathrm{~g}$ and held for $15 \mathrm{~s}$. The microhardness in samples before the SIMA process was determined on the dendrite core and interdendritic regions and after the SIMA process in the globular and the interglobular regions. Also, the microhardness of the aluminum-rich $\alpha$ phase and the zinc-rich $\eta$ phase were determined in both alloys.

\section{Results and Discussion}

\subsection{Microstructure of the as cast alloys}

The different phases present in the as-cast ZA27 and ZA27-2\%Cu-0.015\%Mg alloys were identified by X-Ray diffraction as shown in Figure 1; the main characteristic of all peaks can be observed in the same figure for both alloys. During the solidification of ZA27 alloy and according to the phase diagram of $\mathrm{Zn}-\mathrm{Al}$, the primary $\alpha$ phase solidified first to form the cores of dendrites surrounded by the $\beta$ phase and the eutectic $\eta+\beta$ phase solidified at the end in the interdendrite regions. However the $\beta$ phase is unstable and, by natural ageing, transforms completely to the typical $\alpha+\eta$ equilibrium phases, therefore, the characteristic peaks of this phase are not present in the DRX pattern. The addition of $\mathrm{Cu}$ to the $\mathrm{ZA} 27$ alloy gives rise to a new $\varepsilon$ phase $\left(\mathrm{CuZn}_{4}\right)$ that solidifies together with the $\eta$ phase in the interdendritic regions ${ }^{10}$.

Figure 2 shows backscattered electron images of as-cast dendritic materials, revealing the multiphase character of the microstructure ${ }^{11,12}$. In both alloys, the dark zone (marker A) is the Al-rich $\alpha$ phase formed in the centre of the dendrite. The grey zone (marker B), surrounding the dendritic arms, corresponds to the $\mathrm{Zn}$-rich $\beta$ phase decomposed in a fine lamellar structure which reveals the eutectoid decomposition where the light-contrasted lamella is the Zn-rich $\eta$ phase. The interdendritic regions show the light-contrasted $\eta$ (marker C) and $\varepsilon$ (marker D) phases.

\subsection{Semisolid microstructure of predeformed alloy}

\subsubsection{Optimal deformation level and heat treatment conditions}

Preliminary experiments were conducted to determine the level of deformation leading to an optimal nucleation to growth ratio of the globular structure; several ZA27 alloy samples were deformed between $10 \%$ and $40 \%$ and then were heat treated at $460{ }^{\circ} \mathrm{C}$ for $20 \mathrm{~min}$. The results showed that the average diameter of the grain size in the semisolid microstructure after heat treatment decreases with the increase of the pre-deformation level from $10 \%$ to $20 \%{ }^{13}$. As reported by Lin et al. ${ }^{5}$ in the AZ91D alloys, the average diameter of the semisolid grains became almost constant for deformations larger than 20\%. Figure 3 illustrates the heat treated structures for two deformation levels; Figure $3 \mathrm{a}$ shows the miscrostructure of $10 \%$ deformation and the Figure $3 \mathrm{~b}$ shows the microstructure of $20 \%$ deformation.

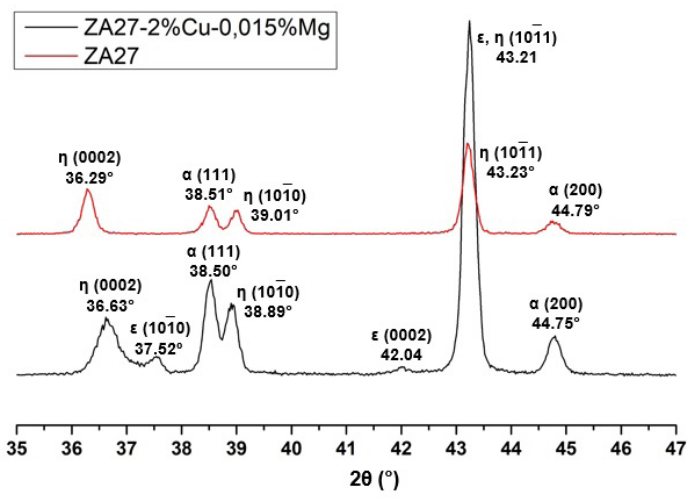

Figure 1. XRD pattern of as-cast ZA27 and ZA27-2\% Cu- $0.015 \% \mathrm{Mg}$ alloys. 

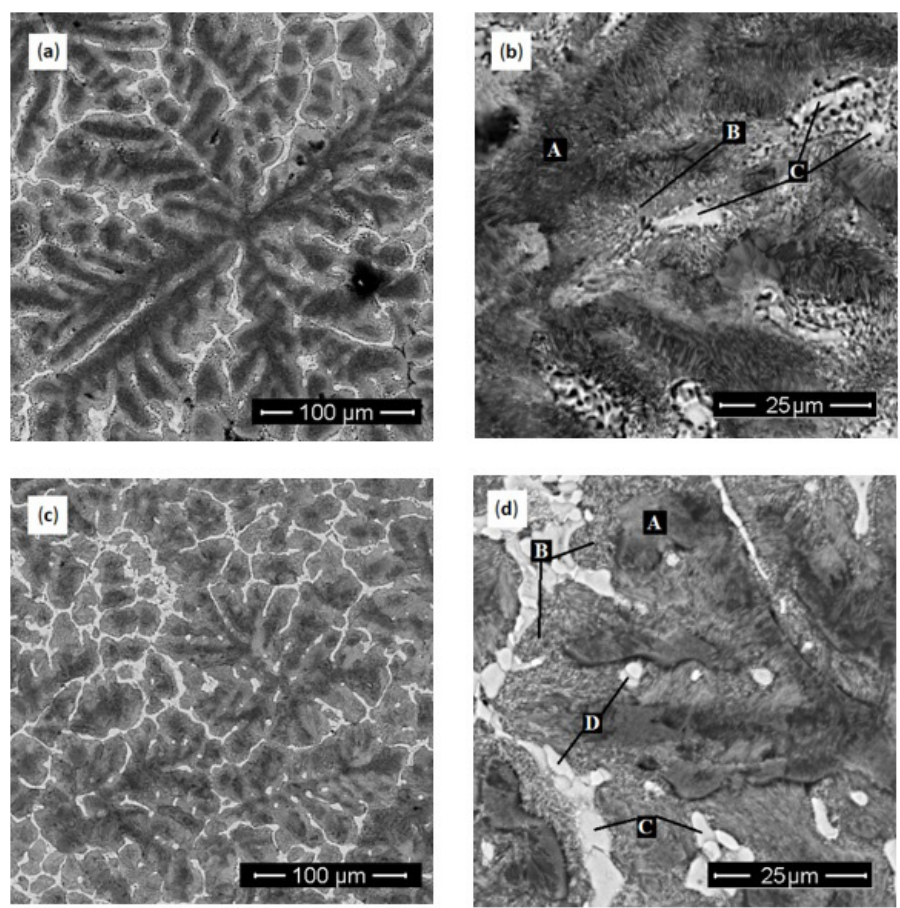

Figure 2. SEM micrographies of dendritic microstructure of the as-cast alloys: (a) and (b) ZA27 alloy; (c) and (d) ZA27-2\%Cu- $0.015 \% \mathrm{Mg}$ alloy. Markers are explained in the main text.

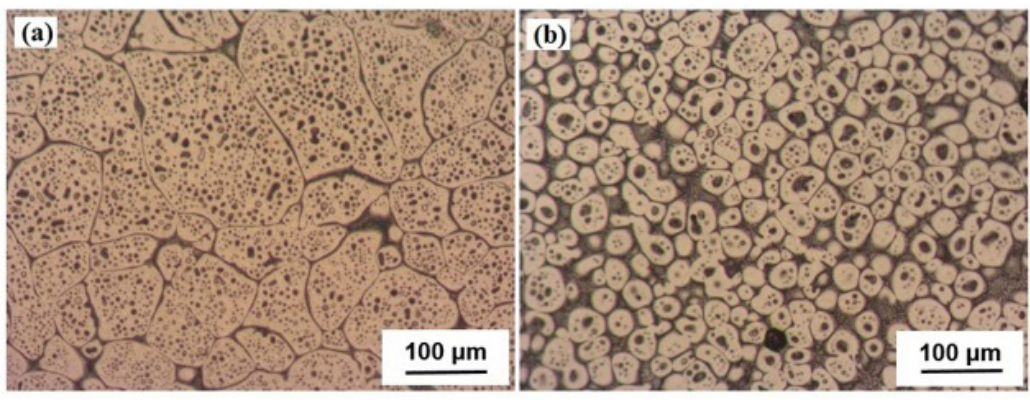

Figure 3. Optical microscope images of ZA27 pure alloys treated at $460{ }^{\circ} \mathrm{C}$ during 20 min and after deformed in thickness: (a) $10 \%$ and (b) $20 \%$.

In the first case the dendrites evolved into very large and irregular non-spherical semi-solid grains and in the second case there is more recrystalization due to a higher deformation energy which results in grains rounder and finer with better processing conditions.

\subsubsection{Surface effect on the globular size distribution}

Since the evolution of the globular structure in the ZA27 alloy during the whole thermal treatment process is followed by metallographic observations at the sample surface after polishing it is important to determine if there is a surface effect on the evolution of the semi-solid structure morphology. In order to do this, the globule size distribution of a sample deformed $20 \%$ and heat treated at $460{ }^{\circ} \mathrm{C}$ during $20 \mathrm{~min}$ was measured at the sample surface and at two different depths from the sample surface: $0.15 \mathrm{~cm}$ and $0.3 \mathrm{~cm}$. These depths were considered adequate, taken into account that the largest measured globular grain was $143.5 \mu \mathrm{m}$ which is approximately 2000 times smaller than the depth of the deeper surface investigated, and therefore, it may be considered far enough from the surface to be affected by any surface effect.

The grain size distributions at the three depths are shown in Figure 4. It is first noted that all the histograms of the globule size distribution are better fitted with the Gamma distribution than with the normal Gaussian distribution since the distributions are slightly skewed to the left. The average size and dispersion obtained from the fitting procedures were: $54.13 \mu \mathrm{m}$ and $22.44 \mu \mathrm{m}$, respectively, at the surface, or level $0 ; 52.53 \mu \mathrm{m}$ and $20.91 \mu \mathrm{m}$ at level 1 ; and $52.96 \mu \mathrm{m}$ and $20.32 \mu \mathrm{m}$ at level 2. Then, considering the size of the statistical sampling performed at each level, the Standard Error of the Mean $\left(\sigma_{M}\right)$ is used. The meaning of $\sigma_{M}$ includes statistical inference based on the sampling distribution and to indicate the precision of the estimated mean of the measurement, the estimated $\sigma_{\mathrm{M}}$ is $0.79 \mu \mathrm{m}$ at the surface of the level $0 ; 0.72 \mu \mathrm{m}$ at level 1 and $0.71 \mu \mathrm{m}$ at level 2 . As it is known, the $\sigma_{M}$ is the standard deviation of the theoretical 


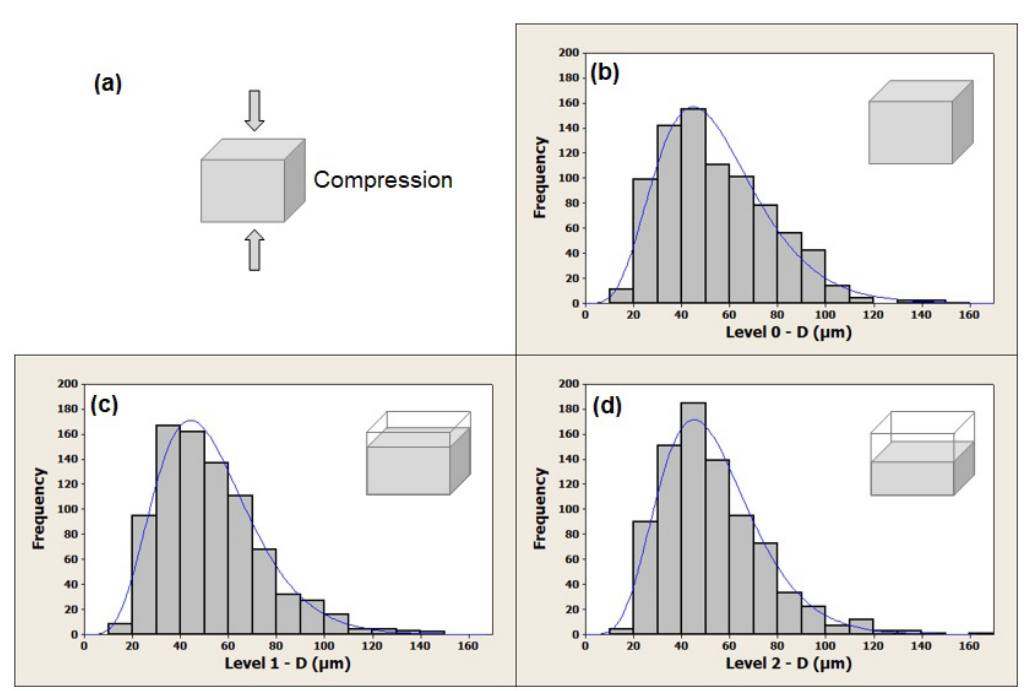

Figure 4. Distribution of grain sizes at different depths of pure ZA27 alloy: (a) The arrow indicates the compression direction, (b) level 0 (surface), (c) level $1(0.15 \mathrm{~cm}$ below surface) and (d) level $2(0.30 \mathrm{~cm}$ below surface).
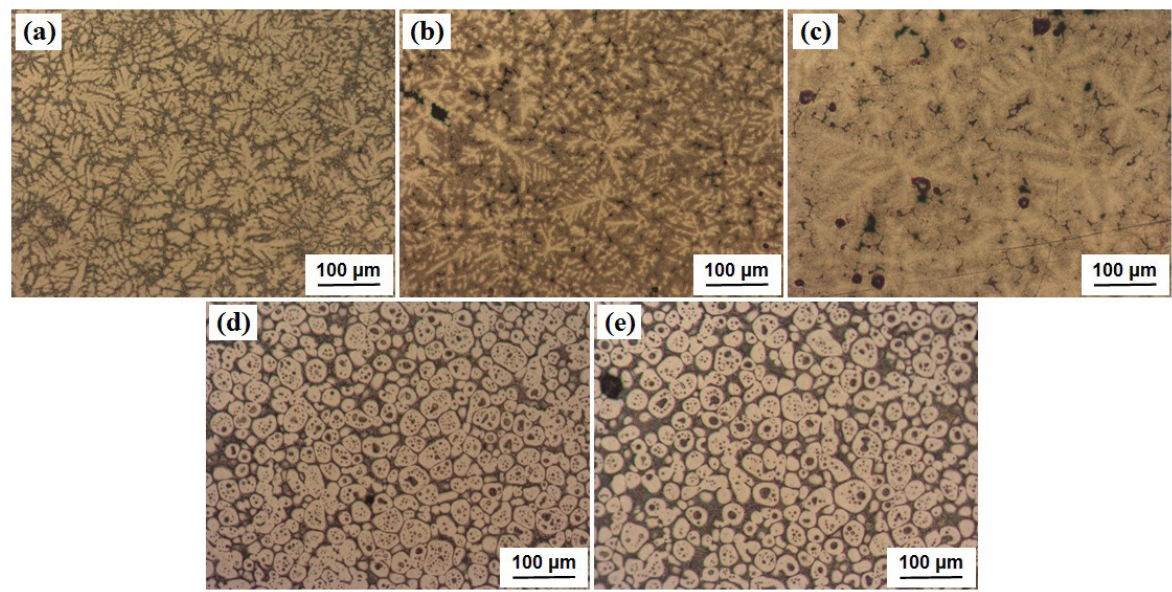

Figure 5. Optical micrographs of the microstructure of the deformed ZA27 alloy (a) when it is partial remelted for (b) $5 \mathrm{~min}$, (c) $10 \mathrm{~min}$, (d) $15 \mathrm{~min}$, (e) $20 \mathrm{~min}$ at temperature of $460{ }^{\circ} \mathrm{C}$ and (d) $15 \mathrm{~min}$.

distribution of the sample mean. From these and considering that the average size in the three leves is the same within the dispersion it may be concluded that there is no surface effect on the spheroidization of the dendritic structure for the ZA27 alloy deformed $20 \%$ in compression and partially remelted at $460^{\circ} \mathrm{C}$ for $20 \mathrm{~min}$.

\subsubsection{Phases and chemical composition of the globular microstructure}

The evolution with time of a stressed dendritic structure to the globular structure achieved after $20 \mathrm{~min}$ of partial remelting at $460{ }^{\circ} \mathrm{C}$ of ZA27 alloy can be seen in Figure 5 a to e. In Figure $5 \mathrm{a}$, it is shown the initial stressed structure of a ZA27 alloy, where the dendrites are still well developed and with an almost unnoticeable deformation. After $5 \mathrm{~min}$ (Figure 5b), the dendrites are still visible, particularly the primary arms, while the secondary arms start to be dissolved but there is still no nucleation or formation of the typical rounded globular structure. With the increase in partial remelting time, the dendritic structure has almost dissapeared being visible some traces of primary arms. The structure transforms into multiple grains which nucleate by a mechanism involving mainly the dendritic cores, in accordance with the phase diagram which predict the survival of the higher temperature $\alpha$ phase much richer in aluminum than the secondary arms (Figure 5c). With further increase of the heating time, the dendritic cores disintegrate due to remelting of their boundary forming spheroidal grains uniformly distributed in a liquid phase (Figure 5d). Furthermore, this globular structure contains intraglobular regions whose morphology suggest that they were quenched from a blocked structure of liquid phase similar to the interglobular one. Some coarsening of the globular structure is noted after $20 \mathrm{~min}$ of partial remelting and the intraglobular regions tend to agglomerate (Figure 5e). In the case of ZA27-2\% Cu- $0.015 \% \mathrm{Mg}$ alloys, the evolution of the microstructure in the same elapsed time show similar results.

Different mechanisms have been proposed to describe the formation of the intraglobular liquid droplets inside the 
globular grains. One of them attributes the formation of the liquid droplet to the segregation from the $\alpha$ phase rich in aluminum which nucleates and grow inside the globular grains ${ }^{14}$. The other mechanism associates the formation of the intraglobular region to a complex process of coalescence of phases ${ }^{15}$. Based on the present results both process may occur simultaneously.

The X-ray diffractograms of the deformed ZA27 and ZA27-2\% Cu- $0.015 \% \mathrm{Mg}$ alloys during partial remelting at $460{ }^{\circ} \mathrm{C}$ are shown in Figures $6 \mathrm{a}$ and $\mathrm{b}$, respectively. The as cast and deformed alloy, taken as initial microstructure, is labeled as $0 \mathrm{~min}$ and the other labels correspond to 5, 10, 15 and $20 \mathrm{~min}$ of heat treatment at $460{ }^{\circ} \mathrm{C}$. As expected, it can be observed that in all the crystallographic phases, the heat treatment does not produce phase transformations in the pure ZA27 alloy.

The evolution of phases during the partial remelting of the ZA27 alloy does not show new phases than those, $\alpha$ and $\eta$, initially detected. Nor can any change in the $\alpha$ phase lattice parameter be observed that could detect a large change in its chemical composition. However, comparing the relative intensity of the $\alpha(111)$ and $\eta(10 \overline{10})$ peaks, it can be said that the volume fraction of the $\alpha$ phase has decreased in the evolution from the dendritic cast material towards the globular structure. This could occur because of the eutectoid decomposition of the $\beta$ phase, which is $\beta \rightarrow \alpha+\eta$, with higher zinc content in the interglobular region with more widely spaced. Therefore, the volume fraction of $\eta$ phase increases at expense of the $\alpha$ phase volume fraction.

In the case of the $\mathrm{ZA} 27-2 \% \mathrm{Cu}-0.015 \% \mathrm{Mg}$ alloy it was observed that there were four phases, $\beta, \eta, \alpha$ and $\varepsilon$ in the asquenched specimen after partial remelting treatment for $20 \mathrm{~min}$. The evolution from the dendritic cast material towards the globular structure by partial remelting shows that the volume fractions of $\eta$ and $\alpha$ phases decrease, while that of the $\beta$ phase increases. The origin of this behavior is similar to that exposed for the ZA27 alloy but now the presence of copper in solution increases the time of eutectoid decomposition.

\subsection{Globular size distribution and composition}

A detailed view of the globular, interglobular and intraglobular zones of the microstructure are shown in
Figure 7 for the ZA27 alloy and Figure 8 for the ZA27 alloyed with $\mathrm{Cu}$ and $\mathrm{Mg}$. Figure 7a corresponds to an SEM image of the ZA27 alloy and Figure 7b-d to the SEM-EDS spectra for the interglobular, globular and intraglobular zones successively. For this alloy, the main two phases are considered: the aluminum-rich $\alpha$ phase or $\alpha$-globular phase and the zinc-rich $\eta$ phase. The $\eta$ phase appears surrounding the $\alpha$-globular phase and also inside the globular phase, they are denominated $\eta$-interglobular and $\eta$-intraglobular, respectively. The compositional map of elements in Figure $7 \mathrm{~b}$, show the distribution of both elements where it is observed that the interglobular and the intraglobular zones are rich in zinc, while the globular zone is rich in aluminum; the respective wt $\%$ compositions are shown in Table 1 . In the case of the ZA27 alloy containing $\mathrm{Cu}$ and $\mathrm{Mg}$, the SEM image of the alloy is shown in Figure 8a and the SEM-EDS spectra are shown in Figure 8a-d. In Figure 8b the map distributions of $\mathrm{Al}, \mathrm{Zn}$ and $\mathrm{Cu}$ are presented, where it is observed that the globular phase is rich in $\mathrm{Al}$, the interglobular and intraglobular phases are rich in $\mathrm{Zn}$ while the $\mathrm{Cu}$ is present in all the microstructure with higher concentrations in the intraglobular and interglobular zones; the respective $\mathrm{wt}^{\mathrm{t}} \%$ compositions are shown in Table 1.

The average composition of the alloys ZA27 and ZA27$2 \% \mathrm{Cu}-0.015 \% \mathrm{Mg}$ were determined in the intraglobular, globular and interglobular regions. The results are shown in Table 1 for aluminum, zinc and copper. With respect to the Aluminum concentration it is observed that for $\mathrm{ZA} 27-2 \% \mathrm{Cu}-$ $0.015 \% \mathrm{Mg}$ the globular region has an average concentration of $54 \%$, which decreases to $14 \%$ in the intraglobular and $19 \%$ in the interglobular regions, whereas for the ZA27 alloy, the composition decreases from $62 \%$ in the globular region to $22 \%$ in the intraglobular and $26 \%$ in the interglobular regions. In the case of the $\mathrm{Zn}$ concentration similar behavior in both alloys is observed, the interglobular and the intraglobular are richer in $\mathrm{Zn}$ than the globular region.

This is indicating that after 20 minutes of heat treatment the composition of each phase is still far from equilibrium; the concentration of the globular region is close to the concentration of the first solid of the dendrite core and that the inter- and intra-globular regions have concentrations of $24 \%$ instead of $17 \%$ as established by the phase diagram. (a)

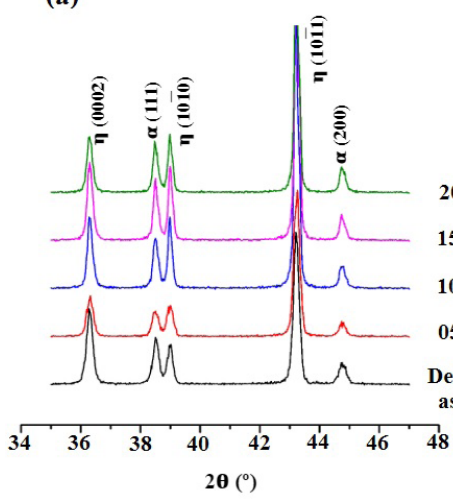

(b)

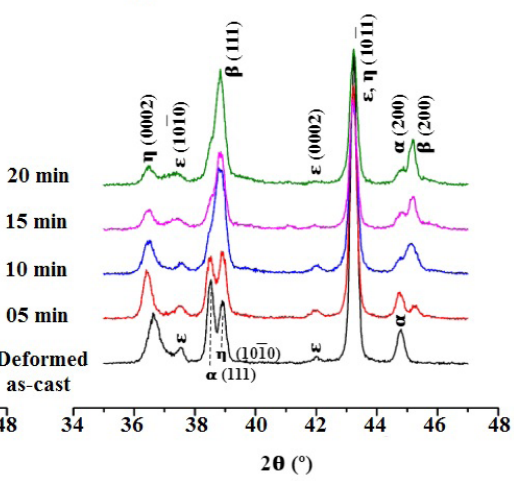

Figure 6. X-ray diffractograms of the deformed sample of the alloys during partial remelting at semi-solid temperature of $460{ }^{\circ} \mathrm{C}$ : (a) ZA27 and (b) ZA27-2\% Cu- $0.015 \% \mathrm{Mg}$. 


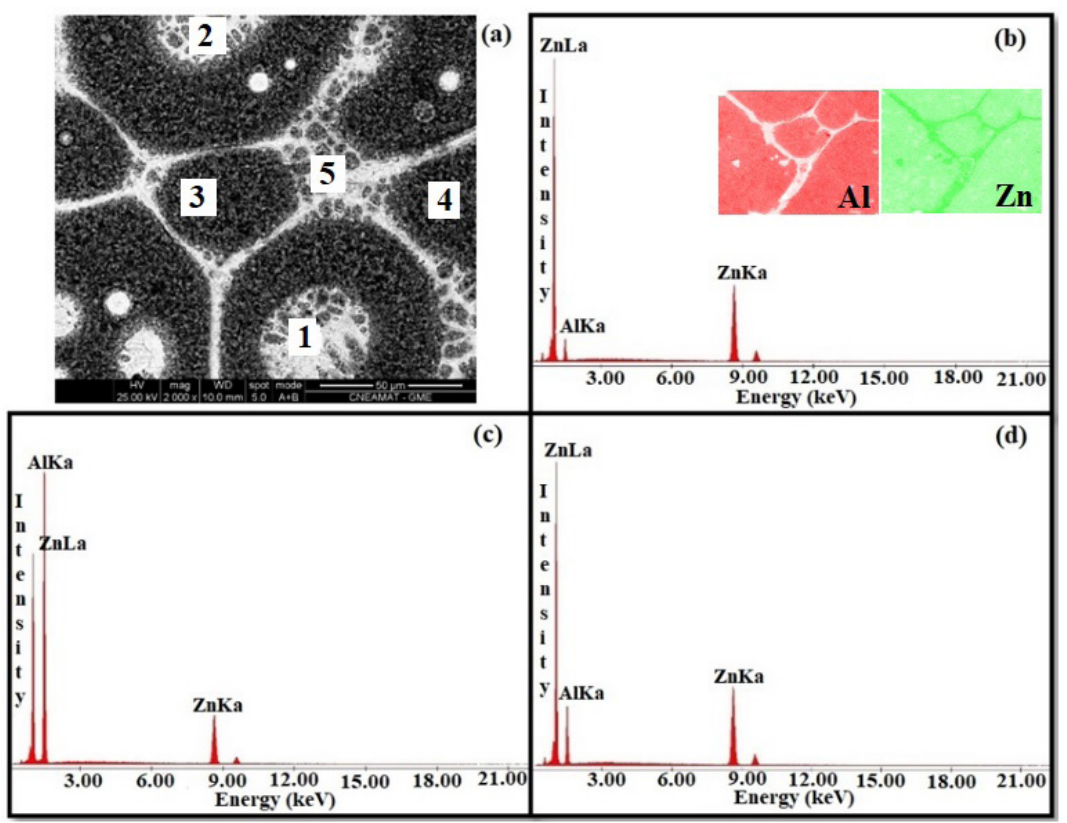

Figure 7. SEM images of ZA27 alloys during $20 \mathrm{~min}$ at $460{ }^{\circ} \mathrm{C}$ : (a) the pure ZA27 alloy with the measuring points by EDAX: (1-2) Intraglobular, (3-4) Globular and (5) Interglobular. (b) EDS spectra of interglobular zone with micrograph of mapping of elements, (c) EDS spectra of globular zone and (d) EDS spectra of intraglobular zone.

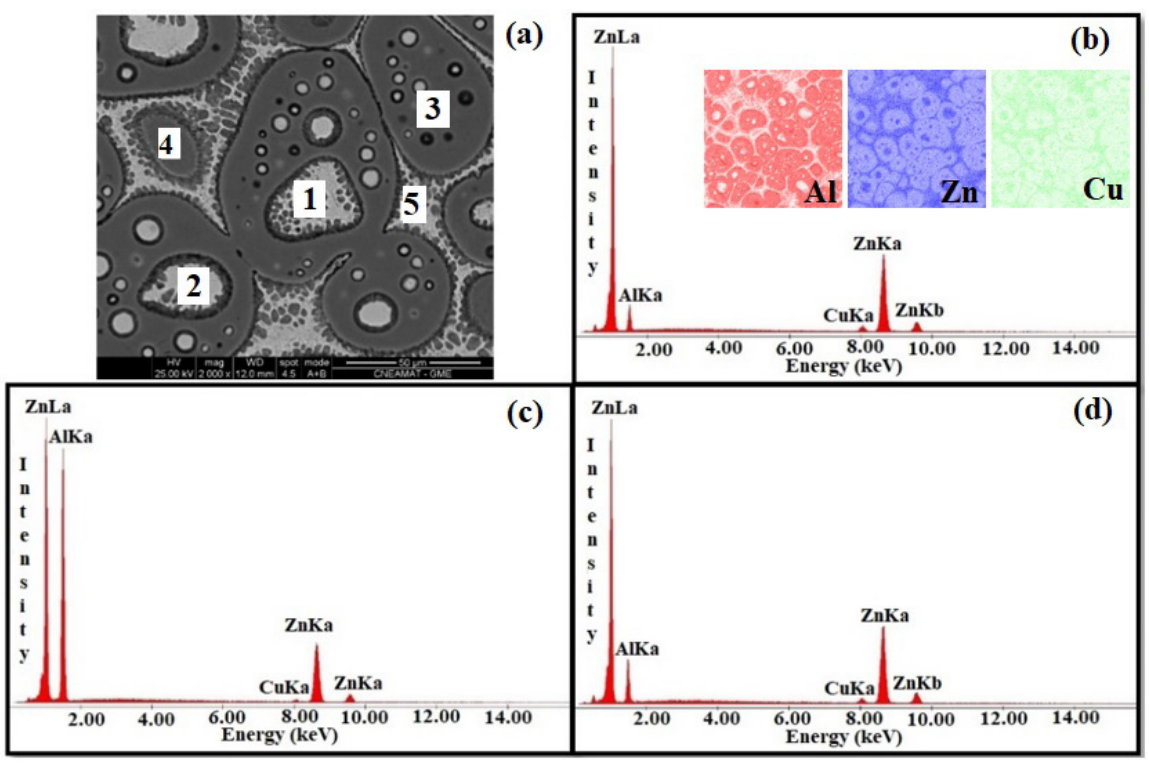

Figure 8. SEM images of ZA27 alloys during $20 \mathrm{~min}$ at $460{ }^{\circ} \mathrm{C}$ : (a) the ZA27 alloy contained $\mathrm{Cu}$ and $\mathrm{Mg}$ with the measuring points by EDAX: (1-2) Intraglobular, (3-4) Globular and (5) Interglobular. (b) EDS spectra of interglobular zone with micrograph of mapping of elements, (c) EDS spectra of globular zone and (d) EDS spectra of intraglobular zone.

Table 1. Composition of both ZA27 alloys, in different zones at $460^{\circ} \mathrm{C}$ during $20 \mathrm{~min}$ of heat treatment obtained from EDS analysis.

\begin{tabular}{|c|c|c|c|c|c|c|}
\hline \multirow{2}{*}{ Position } & \multirow{2}{*}{ Zone } & \multicolumn{2}{|c|}{ ZA27 alloy } & \multicolumn{3}{|c|}{ ZA27-2\%Cu- $0.015 \% \mathrm{Mg}$ alloy } \\
\hline & & $\mathrm{w}(\mathrm{Al}) \%$ & $\mathrm{w}(\mathrm{Zn}) \%$ & $\mathrm{w}(\mathrm{Cu}) \%$ & $\mathrm{w}(\mathrm{Al}) \%$ & $\mathrm{w}(\mathrm{Zn}) \%$ \\
\hline 1 & Intraglobular & 30.99 & 69.01 & 4.29 & 15.61 & 80.10 \\
\hline 2 & Intraglobular & 12.61 & 87.39 & 4.62 & 12.68 & 82.7 \\
\hline 3 & Globular & 62.84 & 37.16 & 1.17 & 53.99 & 44.84 \\
\hline 4 & Globular & 61.63 & 38.37 & 1.29 & 53.87 & 44.84 \\
\hline 5 & Interglobular & 25.51 & 74.49 & 3.91 & 18.63 & 77.46 \\
\hline
\end{tabular}




\subsection{Coarsening of the globular structure}

The rheological properties of a semisolid metallic alloy depend on the relative amount of solid phase, the volume fraction of entrapped liquid ${ }^{8,12}$ as well as their size and shape. Therefore it results necessary to determine how these variables evolve during heat treatment; in particular for the present alloy ZA27 with one solid globular phase and two liquid phases: interglobular and intraglobular. The solid globular phase which contains the intraglobular phase behaves as the solid phase that will define the rheological properties. For the study of coarsening of the globular structure specifically, the initial globular distribution is defined and adopted when it is completely developed. In the present experiments the globular structure is fully developed after 15 minutes of heat treatment at the selected temperature of $460{ }^{\circ} \mathrm{C}$.

Each deformed ZA27 sample was then heat treated at $460{ }^{\circ} \mathrm{C}$ for only one of the following periods of time: 15,20 , 30,45 and 60 min respectively; that is, the heat treatment time is not accumulative. The evolution of the microstructure is shown in Figure 9a-e corresponding to observations under the optical microscope. The initial dendritic structure breaks into a globular structure after $15 \mathrm{~min}$ at $460^{\circ} \mathrm{C}$ as observed in Figure 9a. After $20 \mathrm{~min}$ the structure is more rounded and the distribution of phases: globular and interglobular are better defined. Each phase corresponding to the original dendritic and interdendritic phases respectively. In addition it is notorious the intraglobular or interdendritic phase present inside the globular phase ${ }^{14}$. After 20 minutes the structure starts to coarsen continuously.

Also, considering that the experiments of heat treatment performed to study the evolution of the globular structure starting from the intial time is not accumulative, that is, each treatment starts from a deformed sample to the final time of 20,30, 45 and 60 minutes, and the initial average size $\mathrm{D}_{0}$ corresponds to one specific distribution at $15 \mathrm{~min}$, it is important to confirm that this reference distribution is reproduced for other samples of the same cast. To determine this, two samples of the same cast of pure ZA27 alloy were heat treated at $460{ }^{\circ} \mathrm{C}$ for 15 minutes simultaneously in the same furnace and the results showed that both samples have the same size distributions as can be observed in Figure 10. The average size in each case are $42.73 \mu \mathrm{m}$ and $42.92 \mu \mathrm{m}$, and standard deviations of $15.7 \mu \mathrm{m}$ and $17.12 \mu \mathrm{m}$, respectively. As it is known, the Standard Error of the Mean $\left(\sigma_{M}\right)$ is the standard deviation of the theoretical distribution of the sample means. The meaning of $\sigma_{\mathrm{M}}$ includes statistical inference based on the sampling distribution, the estimated $\sigma_{\mathrm{M}}$ in this case is $0.52 \mu \mathrm{m}$ for the average size $\mathrm{D}_{0-1}$ and $0.59 \mu \mathrm{m}$ for the average size $D_{0-2}$ respectively. This result confirms the reproducibility of the distribution taken as initial reference for the coarsening studies. In the case of ZA27-2\% $\mathrm{Cu}-0.015 \% \mathrm{Mg}$ alloys the results were similar.

In Figure 11 the coarsening of the globular phase is represented as a function of time starting at $15 \mathrm{~min}$ of heat treatment for the two alloys, ZA27 and ZA27-2\%Cu-
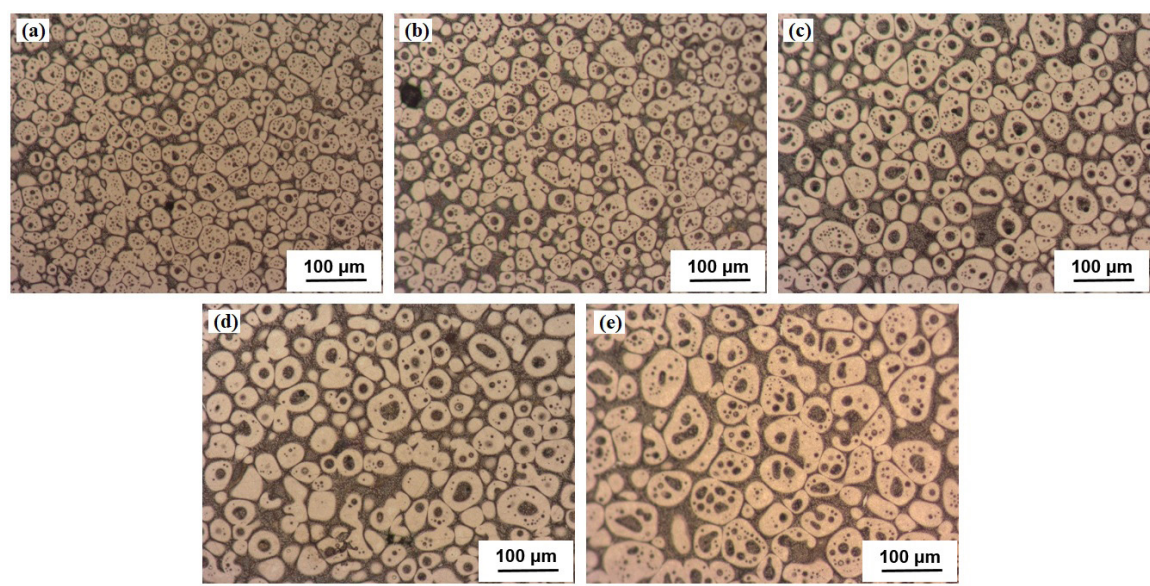

Figure 9. Evolution of phases and species distribution of pure ZA27 alloys thermally treated at $460{ }^{\circ} \mathrm{C}$ at different time: (a) 15 min, (b) $20 \mathrm{~min}$, (c) $30 \mathrm{~min}$, (d) $45 \mathrm{~min}$ and (e) $60 \mathrm{~min}$.
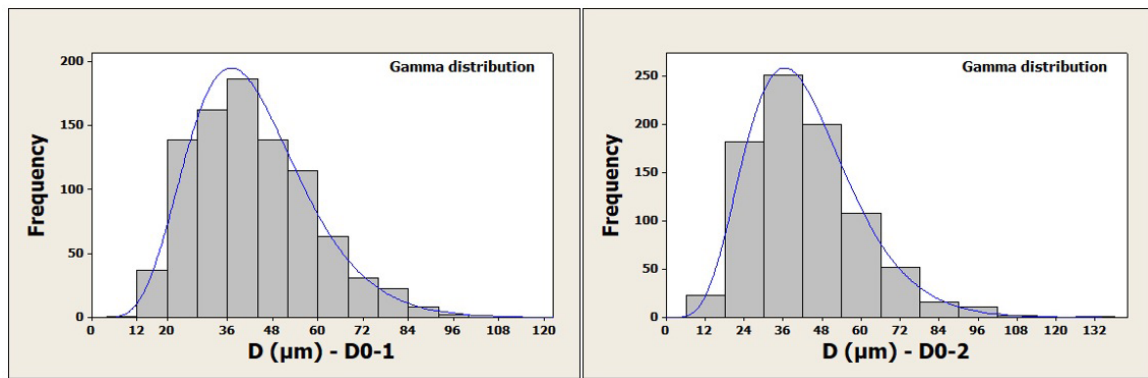

Figure 10. The distribution of initial average size $\mathrm{D}_{0}$ for two samples of the pure $\mathrm{ZA} 27$ alloy at $460^{\circ} \mathrm{C}$ during 15 minutes. 
$0.015 \% \mathrm{Mg}$. In the figure, the ordinate is $\mathrm{D}_{\mathrm{t}}^{3}-\mathrm{D}_{0}^{3}$ which represent the coarsening of the globular phase following the Ostwald ripening theory, where $\mathrm{D}_{\mathrm{t}}$ is the size at time $\mathrm{t}$ and $\mathrm{D}_{0}$ is the size at $15 \mathrm{~min}$ of heat treatment at $460{ }^{\circ} \mathrm{C}$. This translated origin of time is a consequence of the fact that after 15 min of heat treatment the dendritic structures noticeably breaks into a globular structure, as shown before and it is the start of the coarsening process. It is observed that both alloys follow the classic law developed by Lifshitz, Slyozov and Wagner (LSW) $)^{10,16}$, given by the following Equation 1:

$$
D_{t}^{3}-D_{0}^{3}=K t
$$

where $\mathrm{t}$ is the time of heat treatment after $15 \mathrm{~min}$ and $\mathrm{K}$ is the coarsening constant. The value of $\mathrm{K}$ for the ZA27 alloy without other alloying elements is $161.44 \mu \mathrm{m}^{3} / \mathrm{s}$ which is larger than the value for the $\mathrm{ZA} 27-2 \% \mathrm{Cu}-0.015 \% \mathrm{Mg}$ of $89.095 \mu \mathrm{m}^{3} / \mathrm{s}$, or $55 \%$ lower than the value for the ZA27 alloy. This difference shows that the coarsening is faster for the ZA27 alloy than for the ZA27-2\%Cu-0.015\%Mg alloy the slower coarsening speed may be attributed to the presence of $\mathrm{Cu}$ distributed in the structure which may have an effect in the diffusion process of the species in the liquid as well as in the solid.

In the distributions shown for the ZA27 alloy in Figure 12 the small globular grains disappear and the large grains increase in size and number following the coarsening mechanism, which is also observed for the $\mathrm{ZA} 27-2 \% \mathrm{Cu}-0.015 \% \mathrm{Mg}$

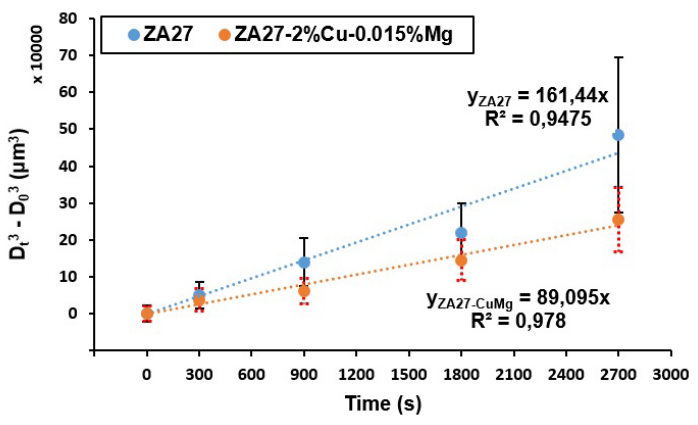

Figure 11. Relationship between $\left(\mathrm{D}^{3}-\mathrm{D}^{3}\right)$ of the grains versus the isothermal time treatment taking $15 \mathrm{~min}$ as initial time $\left(\mathrm{t}_{0}\right)$. alloy shown in Figure 13. As mentioned before, the best adjustment for both alloys is a Gamma distribution, which provides a suitable model for histograms that have a certain type of asymmetry, which in this case show distributions which are a little skewed to the left.

Comparing in Table 1 , the $\mathrm{Zn}$ and $\mathrm{Al}$ concentrations in the intraglobular, globular and interglobular regions it is observed that for the ZA27 alloy the concentrations in the three regions are notably different than those for the ZA27-2\% Cu- $0.015 \% \mathrm{Mg}$. In the case of the $\alpha$-globular region, the average $\mathrm{Zn}$ concentrations are $38 \%$ for the pure ZA27 and $45 \%$ for the ZA27 countaining $\mathrm{Cu}$ and $\mathrm{Mg}$ alloys respectively. However, the relative average concentration of $\mathrm{Zn}$, is notably lower in the pure ZA27 alloy than those for the $\mathrm{ZA} 27-2 \% \mathrm{Cu}-0.015 \% \mathrm{Mg}$ in the intraglobular and interglobular regions. For the pure ZA27 alloy the average concetration of $\mathrm{Zn}$ is $78 \%$ in the intraglobular and $74 \%$ in the interglobular regions, whereas in the other ZA27 alloy the average concentracion of $\mathrm{Zn}$ are $81 \%$ and $77 \%$ for the intraglobular and interglobular regions respectively. It is noted that in the pure ZA27 alloy the $\mathrm{Zn}+\mathrm{Al}$ concentration is $100 \%$, however in the $\mathrm{ZA} 27-2 \% \mathrm{Cu}-0.015 \% \mathrm{Mg}$ is about $99 \%$ in the $\alpha$-globular region and about $96 \%$ in the interglobular and intraglobular regions. That is, it may be inferred as it is shown below, that copper is mainly segregated to the interglobular and the intraglobular regions in the alloyed ZA27 samples. As observed in Table 1, where the evolution of the average concetration of $\mathrm{Cu}$ during heat treatment is quantified for the three regions. It is observed first; that there is no significant effect of the heat treatment, and second; that the $\mathrm{Cu}$ is mostly present in the interglobular and intraglobular regions with concentration of about $4 \% \mathrm{Cu}$ approximately in both regions and $1 \% \mathrm{Cu}$ in the globular region; that is, copper is segregated to the $\eta$ phase which during the melting, casting and heat treatment remains in the liquid state. As suggested above the higher presence of copper in the liquid interglobular and intraglobular phase may be the cause of a slower coarsening of the $\mathrm{ZA} 27-2 \% \mathrm{Cu}-0.015 \% \mathrm{Mg}$ alloy with respect to the coarsening rate of the ZA27 alloy.

It is also remarked that the distributions maintain the overall shape which nearly fit a normal Gaussian distribution, however since they are a little skewed to the left, they are better fitted by the Gamma distribution. Non Gaussian distributions have been extensively used in the literature

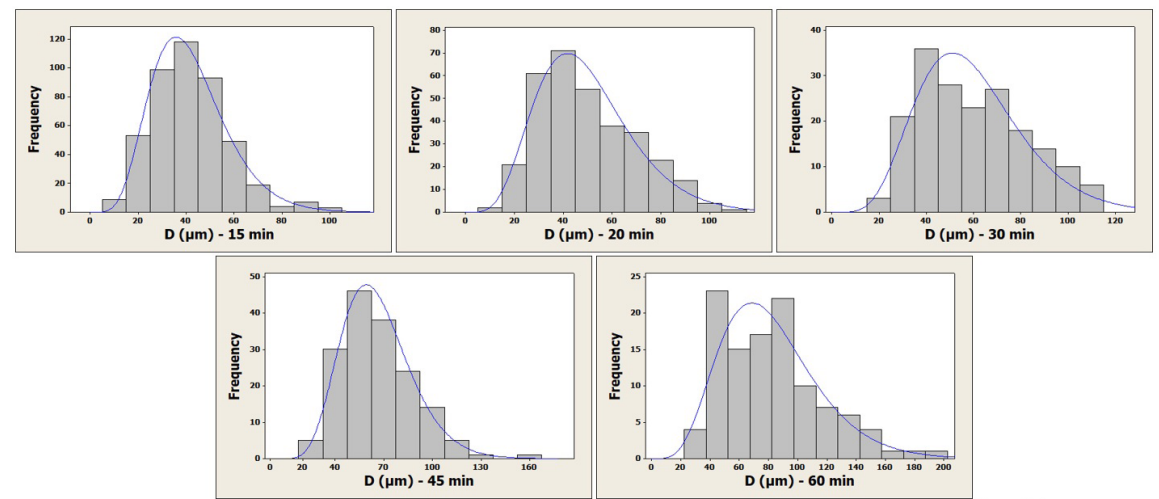

Figure 12. Particle size frequency distribution of the pure ZA27 alloy during the heat treatment. Adjusted to Gamma distribution. 


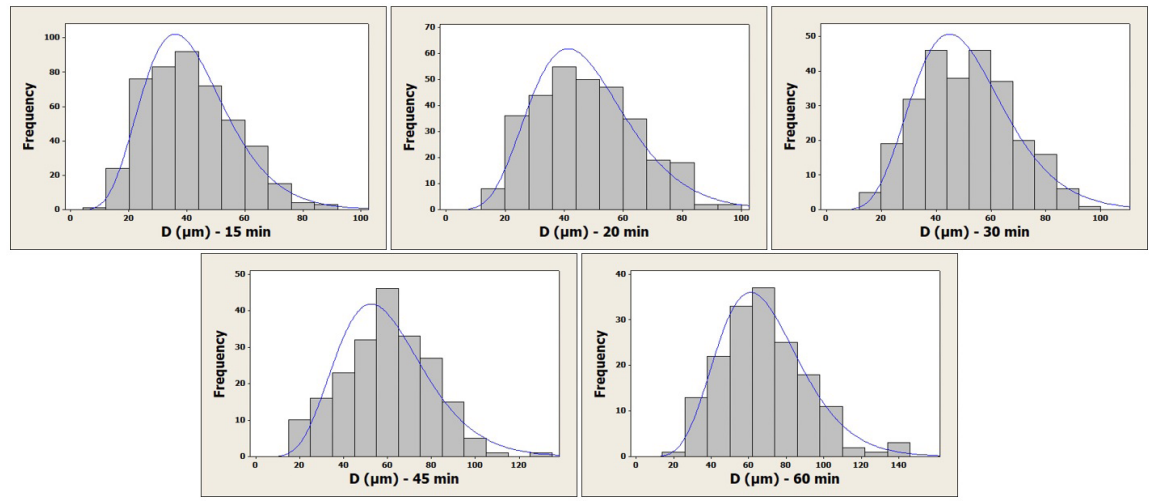

Figure 13. Particle size frequency distribution of the ZA27-2\% Cu- $0.015 \% \mathrm{Mg}$ alloy during the heat treatment. Adjusted to Gamma distribution.

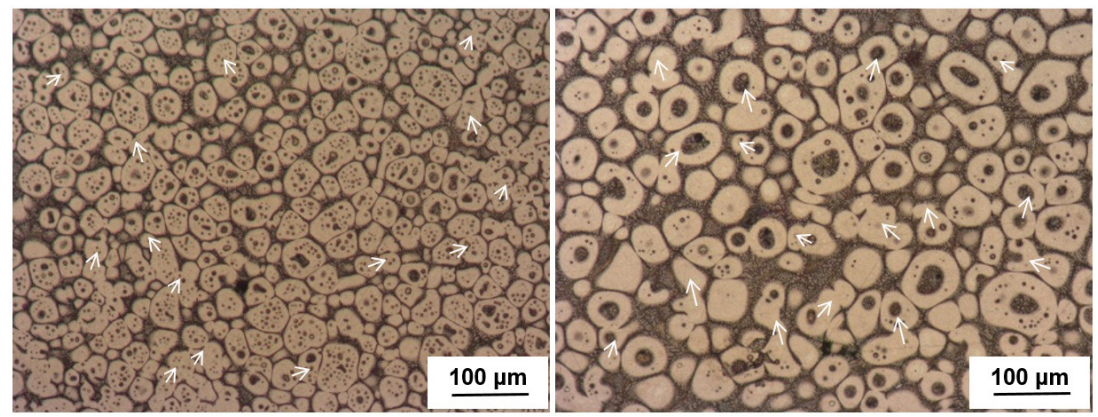

Figure 14. Coalescence of pure ZA27 alloys during the heat treatment (a) $15 \mathrm{~min}$ and (b) $45 \mathrm{~min}$.

Table 2. Experimental mean values of ZA27 alloys.

\begin{tabular}{|c|c|c|c|c|c|c|}
\hline \multirow{2}{*}{ TIME (min) } & \multicolumn{3}{|c|}{ ZA27 } & \multicolumn{3}{|c|}{$\mathrm{ZA} 27-2 \% \mathrm{Cu}-0,015 \% \mathrm{Mg}$} \\
\hline & $\mathrm{D}(\mu \mathrm{m})$ & $\sigma(\mu \mathrm{m})$ & $\sigma / \mathrm{D}(\%)$ & $\mathrm{D}(\mu \mathrm{m})$ & $\sigma(\mu \mathrm{m})$ & $\sigma / \mathrm{D}(\%)$ \\
\hline 15 & 41.77 & 15.83 & 38 & 41.49 & 15.04 & 36 \\
\hline 20 & 49.77 & 19.81 & 40 & 47.62 & 16.99 & 36 \\
\hline 30 & 59.68 & 22.49 & 38 & 51.03 & 16.94 & 33 \\
\hline 45 & 66.32 & 22.14 & 33 & 60.04 & 19.9 & 33 \\
\hline 60 & 82.34 & 34.41 & 42 & 68.92 & 23.06 & 33 \\
\hline
\end{tabular}

including the case of semisolid processing of 7075 alloy ${ }^{17}$ with a low liquid fraction of $10 \%$. Moreover, it has been shown that, ${ }^{18}$ the particle size distributions in a $\mathrm{ZA} 27+2 \% \mathrm{Cu}$ are initially Gaussian and with time of heat treatment at $460{ }^{\circ} \mathrm{C}$ an up to $1440 \mathrm{~min}$, they flatten and skew to larger sizes. The distribution at $30 \mathrm{~min}$ is very similar to those shown in the present research. For longer heat treatment time the skew to larger sizes of the particle size distribution is also present in other alloys like $\mathrm{Al}-4 \% \mathrm{Cu}$ processed in the semisolid state $^{19}$ and during the coarsening of cubic precipitates in solid dilute $\mathrm{Al}$ base $\mathrm{Zr}-\mathrm{V}$ alloys ${ }^{20}$.

Coalescence has been observed in the present research in an extent which has not been quantified. In Figure 14 the white arrow shows a coalescence of globules, which is defined as the nearly instantaneous formation of two or more particles in contact with each other ${ }^{18}$. The coalescence is a mechanism that is usually associated with the formation of entrapped liquid, which is a portion of the liquid phase that is surrounded by the solid phase, and it can occur in dendritic microstructures when secondary arms coalesce ${ }^{21}$. An example of coalescence is observed in Figure 14 for alloy ZA27 during heat treatment at $460{ }^{\circ} \mathrm{C}$; during the first 15 min of heat treatment in Figure 14a the globular grains are closely adjacent and connected together as indicated with white arrows surrounded by liquid trapped inside the grains. At 45 min of heat treatment in Figure 14b the number of grains and therefore the coalescence by contact of grains decreases.

The growth kinetic of globules in all cases follows the law of the third power of D vs t. Also, the broadness is similar in all cases with values of $\sigma$ as listed in Table 2 of around $30 \%$ of the value of the average globular size.

Kuehmann and Voorhees have studied ripening theoretically in solid ternary alloys in which one of the components has low concentrations ${ }^{22}$, in the present ZA alloy two of the four components are in low concentration. They found that the coarsening rate $\mathrm{K}$ is a function of the distribution coefficient, the equilibrium solubility, and the diffusion coefficient of the components. For instance, assuming similar partition coefficient for the components, if the diffusion coefficients of the components are similar, the addition of a third will reduce the rate constant. On the other hand if the third element has a much higher diffusion, 
the addition of a slower element will largely reduce the ripening rate. It is noted that in the ZA27 alloys the second element, $\mathrm{Al}$, is present in a high concentration with respect to the third element $\mathrm{Cu}$, and the theory was developed for a dilute alloy with two minority alloying elements. Nevertheless, in Figure 11 the value of $\mathrm{K}$ for the pure ZA27 alloy is $161.44 \mu \mathrm{m}^{3} / \mathrm{s}$ and for the ZA27 containing $2 \% \mathrm{Cu}$ the value of $\mathrm{K}$ is $89.095 \mu \mathrm{m}^{3} / \mathrm{s}$, that is $55 \%$ lower than the value for the pure ZA27 alloy in agreement with the description mentioned above about the third component.

Specifically in semisolid ZA27 alloys it has been found ${ }^{18}$ experimentally that addition of elements like rare-earth (RE) $(0.8 \%$ in mass) and $\mathrm{Mg}(2 \%$ in mass) in ZA27 alloys containing around $2 \% \mathrm{Cu}$ has the effect of reducing the coarsening rate constant. It is proposed that $\mathrm{RE}$ (or $\mathrm{Ce}$ ) with a layer atomic radius affect the diffusion of the smaller $\mathrm{Zn}$ and $\mathrm{Al}$ atoms, and also hindered the coalescence of the solid particles. In the case of $\mathrm{Mg}$, it reduces the solid fraction separating the solid globules, increasing the diffusion distance and reducing coalescence by decreasing particle impingement. It is expected that similar mechanism has applied in the present research.

\subsection{Microhardness of both alloys}

The indentations of the microhardness measurements for the as cast ZA27 alloy are shown in Figure 15 for the two main components of the microstructure; the dendrite core formed by the aluminum-rich $\alpha$ phase in Figure 15a and the zinc-rich $\eta$ phase of the interdendritic region in Figure $15 \mathrm{~b}$. The microhardness measurements after the compression and heat treatment during the SIMA process are shown in Figure 15 for the other main regions of the microstructure; the aluminum-rich globular phase in Figure $15 \mathrm{c}$ and for the zinc-rich interglobular phase in Figure 15d.

For the as cast alloys the results show that in the case of the ZA27 alloy the microhardness of the dendrite core is $94.86 \pm 4.34 \mathrm{kgf} / \mathrm{mm}^{2}$ and for the interdendritic region is $66.67 \pm 5.76 \mathrm{kgf} / \mathrm{mm}^{2}$. For the ZA27 alloy containing $\mathrm{Cu}$ and $\mathrm{Mg}$, the microhardness in the respective regions are $127.15 \pm 11.1 \mathrm{kgf} / \mathrm{mm}^{2}$ and $123.16 \pm 7.29 \mathrm{kgf} / \mathrm{mm}^{2}$. These results show that the ZA27 without other alloying elements is softer than the alloyed one. In addition, in the ZA27 alloy the dendrite cores are stronger than the interdendritic region, which is not the case for the ZA27 alloy containing $\mathrm{Cu}$ and the $\mathrm{Mg}$ where both; dendritic and interdendritic regions have similar microhardness values.

The results of microhardness measurements after heat treatment are shown in Figure 16; Figure 16a corresponds to the pure ZA27 alloy and Figure $16 \mathrm{~b}$ to the alloyed ZA27 with $\mathrm{Cu}$ and $\mathrm{Mg}$. Both alloys during the SIMA
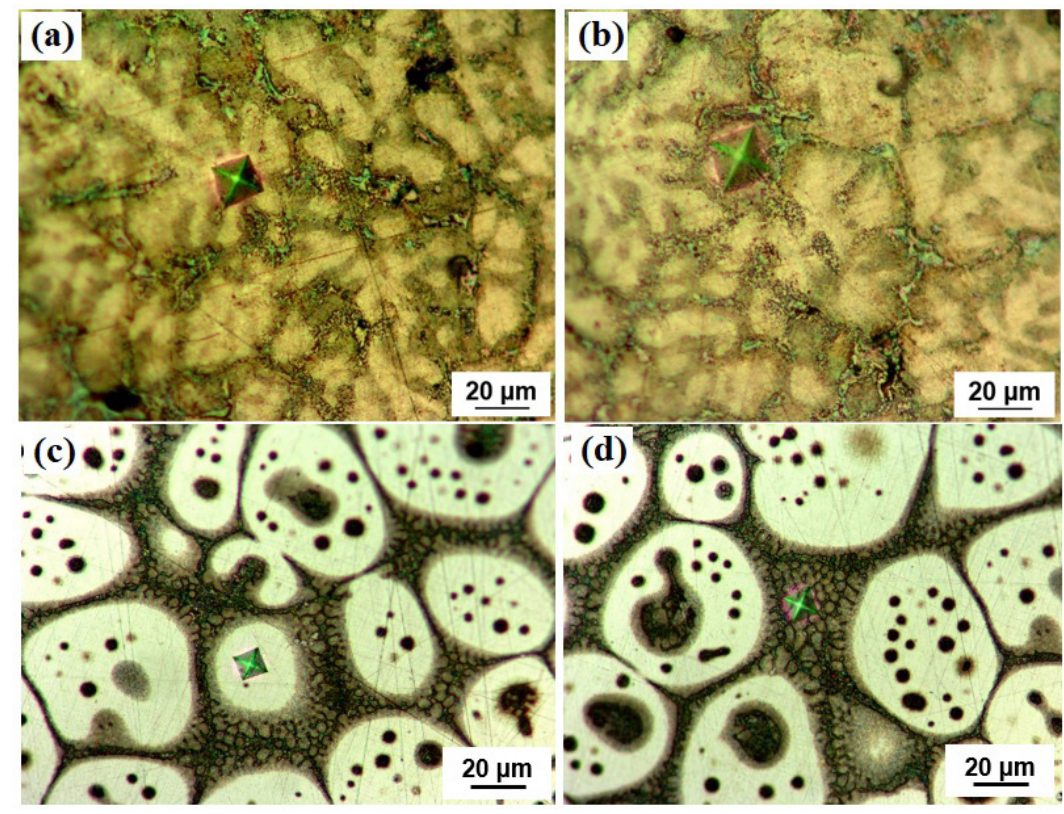

Figure 15. Microhardness of the as-cast of ZA27 pure alloy before and after the SIMA process applied: a) indentation of the dendrite score, (b) indentation of the interdendritic region, (c) indentation of the globular phase and (d) indentation of the interglobular phase.

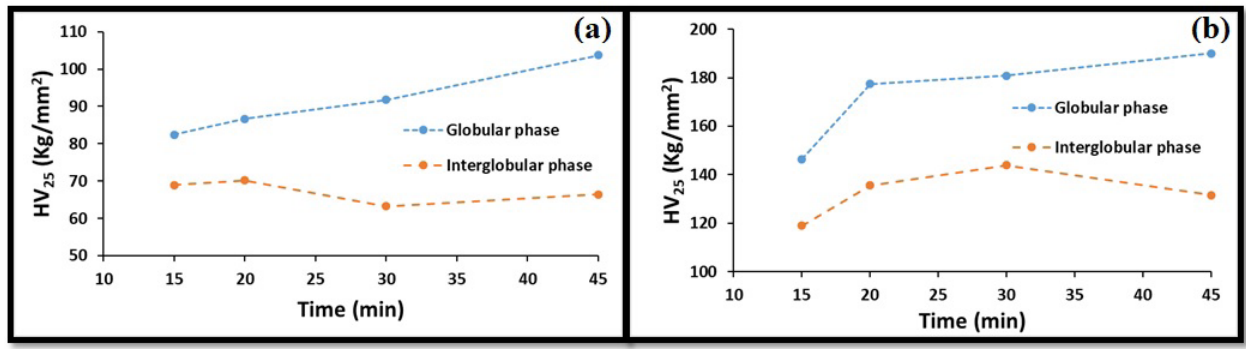

Figure 16. Microhardness of the ZA27 and the ZA27-2\% Cu- $0.015 \% \mathrm{Mg}$ alloys, treated at $460^{\circ} \mathrm{C}$ with the heating time. 
process increase their microhardness in the globular phase and the interglobular region. The increase in the case of the aluminum-rich globular phase could be associated to the larger and more homogeneous structure due to coarsening of grains. The microstructure of the interglobular region is a non-homogeneous structure and this can cause the scatter of the values compared to the results on the globular structure.

Comparing the microhardness values of the ZA27 alloy with the alloyed ZA27 alloy, it is observed that the ZA27 alloy containing $\mathrm{Cu}$ and $\mathrm{Mg}$ presents microhardness which is almost twice as higher than for the ZA27 alloy in both of the main phases. The microhardness of the globular phase in both alloys increased with the time of heat treatment, while the interglobular region shows more variation. The increase of the microhardness in the alloyed ZA27 could be attributed to presence of $\mathrm{Cu}$ almost homogeneously distributed in both the globular and the interglobular regions, and as mentioned in the literature, the hardness increases almost continuously with increasing copper content ${ }^{23}$.

\section{Conclusions}

The microstructure and characterization of both alloys after the heat treatment have been studied, the microhardness of the globular and the interglobular phases has been tested. From these experiments, the following conclusions have shown.

1. The multiphase character of the as-cast dendritic microstructure of both ZA27 alloys consists of dendrites of Al-rich $\alpha$ phase formed in the center, surrounded by the $\mathrm{Zn}$-rich $\beta$ phase decomposed in a fine lamellar structure which reveals the eutectoid decomposition, and the Zn-rich $\eta$ phase in the interdendritic region. The addition of $\mathrm{Cu}$ to the $\mathrm{ZA} 27$ alloy gives rise to a new $\varepsilon$ phase $\left(\mathrm{CuZn}_{4}\right)$ in the interdendritic region.

2. The heat treatment does not produce phase transformations in the pure ZA27 alloy, the evolution of phases during the partial remelting of the ZA27 alloy does not show new phases than those, $\alpha$ and $\eta$, initially detected. The ZA27 alloyed with $\mathrm{Cu}$ and $\mathrm{Mg}$ presents phase transformations, four phases, $\beta, \eta, \alpha$ and $\varepsilon$ appear in the as-quenched specimen after partial remelting for $20 \mathrm{~min}$.

3. The evolution from the dendritic as-cast material towards the globular structure by partial remelting shows that the volume fractions of $\eta$ and $\alpha$ phases decrease, while that of the $\beta$ phase increases with the hold time, this provokes the dissoluction of $\alpha$ and $\eta$ phases into the $\beta$ phase.

4. There is no significant surface effect of the heat treatment process on the microstructure at the sample surface and the depth of the samples analyzed.

5. The average grains size increased with the holding time and both alloys followed the classic law developed by Lifshitz, Slyozov and Wagner (LSW), used to describe the particle coarsening behavior. The addition of $\mathrm{Cu}$ and $\mathrm{Mg}$ reduced the coarsening rate of the ZA27 alloyed, 55\% lower than the pure ZA27 alloy.

6. The best semisolid structure is obtained for both alloys, ZA27 and ZA27 alloyed with $\mathrm{Cu}$ and $\mathrm{Mg}$ after 15 minutes of heat treatment at $460{ }^{\circ} \mathrm{C}$, with small rounded globular structures. After this, the globular phase starts to coarsen.

7. The microhardness of the globular phase increases with the holding time of heat treatment, while the interglobular region shows more variation because of the non-homogeneous structure of this phase of both alloys. ZA27 alloy containing $\mathrm{Cu}$ and $\mathrm{Mg}$ is almost twice as high as the microhardness of the ZA27 alloy in both of the main phases.

\section{Acknowledgments}

One of the authors thanks the National Scientific and Technical Research Council (CONICET, Argentina) for the Doctoral Scholarship. We acknowledge the support of Silvia Adriana Dominguez for the Electron Microscopy Laboratory analysis at CAC (Centro Atómico Constituyentes), Gerencia Materiales de Buenos Aires.

\section{References}

1. Ti-jun C, Yuan H, Jun S. Microstructural evolution and phase transformations of mechanically stirred non-dendritic ZA27 alloy during partial remelting. J Wuhan Univ Technol Sci Ed. 2004;19(4):56-61.

2. Chen TJ, Hao Y, Sun J. Microstructural evolution of previously deformed ZA27 alloy during partial remelting. Mater Sci Eng A. 2002;337(1-2):73-81.

3. Jiang H, Li X, Xiong A, Li M. Fabrication and microstructure evolution of semi-solid LY11 alloy by SIMA. J Mater Eng Perform. 2003;12(3):249-53.

4. Jiang H, Li M. Microscopic observation of cold-deformed Al$4 \mathrm{Cu}-\mathrm{Mg}$ alloy samples after semi-solid heat treatments. Mater Charact. 2005;54(4-5):451-7.

5. Lin HQ, Wang JG, Wang HY, Jiang QC. Effect of predeformation on the globular grains in AZ91D alloy during strain induced melt activation (SIMA) process. J Alloys Compd. 2007;431(1-2):1417.

6. Binesh B, Aghaie-Khafri M. Microstructure and texture characterization of $7075 \mathrm{Al}$ alloy during the SIMA process.

Mater Charact. [serial on the Internet]. 2015 Aug 1 [cited 2019 Feb 6];106:390-403. Available from: https://www.sciencedirect. com/science/article/pii/S1044580315002193

7. Flemings MC. Behavior of metal alloys in semi-solid state. Met Trans B. 1991;22B:269-93.

8. Tzimas E, Zavaliangos A. Evolution of near-equiaxed microstructure in the semisolid state. Mater Sci Eng A. 2000;289(1-2):228-40.

9. Ti-jun CHEN, Ying MA, Yuan HAO, Song LU, Guang-ji XU, Jun SUN. Strutural evolution of Za27 alloy during semisolid isothermal heat treatment. Nonferrous Met Soc China. 2001;11(1):98-102.

10. Liu Y, Li HY, Jiang HF, Lu XC. Effects of heat treatment on microstructure and mechanical properties of ZA27 alloy. Trans Nonferrous Met Soc China. 2013;23(3):642-9.

11. Auras R, Schvezov C. Wear behavior, microstructure, and dimensional stability of as-cast zinc-aluminum/SIC (metal matrix composites) alloys. Metall Mater Trans, A Phys Metall Mater Sci. [serial on the Internet]. 2004 [cited 2019 Feb 6];35(5):1579-90. Available from: http://www.zid.tuwien.ac.at/ fileadmin/files_zid/projekte/2010/10-202-1.pdf

12. Durman M, Murphy S. An electron metallographic study of pressure die-cast commercial zinc-aluminium-based alloy ZA27. J Mater Sci. 1997;32:1603-11.

13. Desrosin W, López I, Rubiolo GH, Schvezov CE. Efecto de la deformación en frío por compresión sobre la evolución 
microestructural en estado semi-sólido de la aleación ZA27. In: Libro de resúmenes extendido del $18^{\circ}$ Congreso Internacional de Metalurgia y Materiales CONAMET-SAM; 2018; Ciudad Autónoma de Buenos Aires. Proceedings. Ciudad Autónoma de Buenos Aires: Editorial Comisión Nacional de Energía Atómica - CNEA; 2018. p. 205-7.

14. Zhang L, Liu YB, Cao ZY, Zhang YF, Zhang QQ. Effects of isothermal process parameters on the microstructure of semisolid AZ91D alloy produced by SIMA. J Mater Process Technol. 2009;209:792-977.

15. Manson-Whitton ED, Stone IC, Jones JR, Grant PS, Cantor B. Isothermal grain coarsening of spray formed alloys in the semi-solid state. Acta Mater. 2002;50:2517-35.

16. Zhang L, Liu YB, Cao ZY, Zhang YF, Zhang QQ. Effects of isothermal process parameters on the microstructure of semisolid AZ91D alloy produced by SIMA. J Mater Process Techol. 2008;209(2):792-7.

17. Mohammadi H, Ketabchi M, Kalaki A. Microstructure evolution of semi-solid 7075 aluminum alloy during reheating process. J Mater Eng Perform. 2011;20(7):1256-63.
18. Chen TJ, Hao Y, Sun J, Li YD. Effects of Mg and RE additions on the semi-solid microstructure of a zinc alloy ZA27. Sci Technol Adv Mater. 2003;4:495-502.

19. Ferrante M, De Freitas E. Rheology and microstructural development of a Al-4wt $\% \mathrm{Cu}$ alloy in the semi-solid state. Mater Sci Eng A. 1999;271(1-2):172-80.

20. Zedalis MS, Fine ME. Precipitation and ostwald ripening in dilute AI Base-Zr-V alloys. Metall Trans A, Phys Metall Mater Sci. 1986;17:2187-98.

21. Campo KN, de Freitas CC, Moon SC, Dippenaar R, Caram R. In-situ microstructural observation of $\mathrm{Ti}-\mathrm{Cu}$ alloys for semisolid processing. Mater Charact. 2018;145:10-9.

22. Kuehmann C, Voorhees P. Ostwald ripening in ternary alloys. Metall Mater Trans, A Phys Metall Mater Sci. [serial on the Internet]. 1996 [cited 2019 Feb 6];27(4):937-43. Available from: http://link.springer.com/10.1007/BF02649761

23. Savaşkan T, Hekimoglu AP, Pürçek G. Effect of copper content on the mechanical and sliding wear properties of monotectoidbased zinc-aluminium-copper alloys. Tribol Int. 2004;37(1):4550 . 